\title{
Predictors and reproducibility of exercise- induced bronchoconstriction in cold air
}

\author{
Melanie Dreßler ${ }^{1 *}$ (D), Theresa Friedrich ${ }^{1}$, Natali Lasowski ${ }^{1}$, Eva Herrmann², Stefan Zielen ${ }^{1}$ and Johannes Schulze
}

\begin{abstract}
Background: Physical activity is an important part of life, and hence exercise-induced bronchoconstriction (EIB) can reduce the quality of life. A standardized test is needed to diagnose EIB. The American Thoracic Society (ATS) guidelines recommend an exercise challenge in combination with dry air. We investigated the feasibility of a new, ATS guidelines conform exercise challenge in a cold chamber (ECC) to detect EIB. The aim of this study was to investigate the surrogate marker reaction to methacholine, ECC and exercise challenge in ambient temperature for the prediction of a positive reaction and to re-evaluate the reproducibility of the response to an ECC.

Methods: Seventy-eight subjects aged 6 to 40 years with suspected EIB were recruited for the study. The subjects performed one methacholine challenge, two ECCs, and one exercise challenge at an ambient temperature. To define the sensitivity and specificity of the predictor, a receiver-operating characteristic curve was plotted. The repeatability was evaluated using the method described by Bland and Altman (95\% Limits of agreement).

Results: The following cut-off values showed the best combination of sensitivity and specificity: the provocation dose causing a 20\% decrease in the forced expiratory volume in $1 \mathrm{~s}\left(\mathrm{PD}_{20} \mathrm{FEV}_{1}\right.$ ) of methacholine: $1.36 \mathrm{mg}$ (AUC 0.69, $p<0.05$ ), the maximal decrease in $\mathrm{FEV}_{1}$ during the ECC: $8.5 \%$ (AUC $0.78, p<0.001$ ) and exercise challenges at ambient temperatures: $\mathrm{FEV}_{1} 5.2 \%$ (AUC 0.64, $p=0.13$ ). The median decline in $\mathrm{FEV}_{1}$ was $14.5 \%$ (0.0-64.2) during the first ECC and $10.7 \%(0.0-52.5)$ during the second ECC. In the comparison of both ECCs, the Spearman rank correlation of the $F E V_{1}$ decrease was $r=0.58(p<0.001)$. The $95 \%$ limits of agreement $(95 \% \mathrm{LOAs})$ for the $\mathrm{FEV}_{1}$ decrease were -17.7 to $26.4 \%$.

Conclusions: The surrogate markers $\mathrm{PD}_{20} \mathrm{FEV}_{1}$ of methacholine and maximal decrease in $\mathrm{FEV}_{1}$ during $\mathrm{ECC}$ can predict a positive reaction in another ECC, whereas the maximal FEV ${ }_{1}$ decrease in an exercise challenge at an ambient temperature was not predictive. Compared with previous studies, we can achieve a similar reproducibility with an ECC.
\end{abstract}

Clinical trial registration: NCT02026492 (retrospectively registered 03/Jan/2014).

Keywords: Exercise-induced bronchoconstriction, Exercise challenge in a cold chamber, Exercise challenge at an ambient temperature, Methacholine challenge test

\section{Background}

Physical activity in the context of playing and sports is an important part of life, particularly among children and adolescents, and contributes to natural development. Hence, exercise-induced bronchoconstriction (EIB) can significantly reduce the quality of life. Additionally, exercise is associated with significant health benefits, such as

\footnotetext{
* Correspondence: melanie.dressler@kgu.de

${ }^{1}$ Division of Pulmonology, Allergy and Cystic Fibrosis, Department of

Paediatric and Adolescent medicine, University Hospital Frankfurt,

Theodor-Stern-Kai 7, 60590 Frankfurt am Main, Germany

Full list of author information is available at the end of the article
}

preventing an overweight status and obesity and reducing the risk factors of cardiovascular disease [1].

Data regarding the epidemiology of EIB range from approximately $10 \%$ in the normal population up to $90 \%$ in patients with severe asthma [2] depending on the exercise challenges used for EIB diagnosis and the challenged patient cohort [3]. For instance, a study involving 10 -year-old Norwegian children showed that $8.6 \%$ of all children had EIB and that EIB occurred significantly more often in children known to have asthma (36.7\%) [4]. Furthermore, the classical symptoms, such as

(C) The Author(s). 2019 Open Access This article is distributed under the terms of the Creative Commons Attribution 4.0 International License (http://creativecommons.org/licenses/by/4.0/), which permits unrestricted use, distribution, and 
dyspnoea, coughing or wheezing during sports, are known to have low sensitivity and specificity in predicting EIB $[2,5,6]$.

Due to these reasons, a standardized test is essential for correctly diagnosing EIB. There are two different categories of bronchial provocation challenges as follows: direct and indirect challenges. In direct challenges, methacholine or histamine directly bind a smooth muscle receptor and cause bronchoconstriction. In indirect challenges, such as exercise, the inhalation of mannitol or hypertonic saline lead to increased osmolarity in the airway surfaces and consecutively to the activation of mast cells and epithelial cells, which are stimulated to release proinflammatory mediators (histamine, leukotrienes, and prostaglandins) that provoke airway smooth muscle contraction $[2,3,7,8]$.

Indirect challenges seem to be more effective in predicting EIB than direct challenges [2,9] and are more specific for asthma, whereas direct tests are more sensitive [10]. The American Thoracic Society (ATS) recommends performing an exercise challenge in dry air, followed by serial lung function tests for the diagnosis of EIB; the cut-off value of a positive exercise challenge is an $\mathrm{FEV}_{1}$ decrease $\geq 10 \%$ [5]. Interestingly, in subjects with mild EIB, more than one exercise challenge is often required to confirm the diagnosis [11]. The reproducibility of two separate exercise challenges in combination with dry air has been reported to be $76 \%$ [12] and the intraclass correlation is good at 0.72 [13]. To diagnose EIB ATS guidelines conform we established an exercise challenge in a cold chamber (ECC) in our outpatient clinic. This method has several advantages. The patients run in a cold chamber on a treadmill without wearing a facemask for the inhalation of dry air, which is especially important in young children. In addition, the ECC simulates natural exercising at cold temperatures since participating in sports in cold environments is known to provoke EIB [14].

In addition to the exercise test, the World Anti-Doping Agency and the International Olympic Committee recommend the use of other methods to confirm the diagnosis of bronchial hyperresponsiveness (BHR) and EIB. The methacholine challenge test (MCT) is a well-established method used to assess BHR $[11,15,16]$. The sensitivity of MCT in predicting EIB ranges from 58.6 to $91.1 \%$ [11, 17]. Other recommended challenges include the inhalation of dry powder mannitol and eucapnic voluntary hyperventilation (EVH). At our department, we have broad experience with MCT $[16,18-20]$; therefore, we selected this specific surrogate for comparison with the ECC.

The first aim of the present study was to determine whether MCT as a well-established test $[11,17]$ is a valuable predictor of EIB. The MCT as a predictor of EIB has been previously investigated in comparison with an exercise challenge at an ambient temperature and a combination of exercise and dry air [11, 17, 21-24], but not in comparison with exercise and cold air. The second aim was to determine the reproducibility of the $\mathrm{FEV}_{1}$ decrease and the area under the curve from 0 to 30 min $\left(\mathrm{AUC}_{0-30 \mathrm{~min}}\right)$ in detecting EIB with the ECC. Good reproducibility is a precondition for anti-asthmatic medication testing and statistical power calculations.

\section{Methods}

\section{Study design}

The open study consisted of four visits. Participation in the study was voluntary and written informed consent was obtained from each subject and the parents of children under the age of 18 years before starting the first visit (V1).

At V1, the inclusion and exclusion criteria were checked, the medical and medication histories were reviewed and a medical examination was performed. All children $<12$ years completed the asthma control test (ACT), and all subjects $\geq 12$ years completed the asthma control questionnaire (ACQ). All subjects performed a lung function test and an MCT.

The second visit (V2) occured between 2 weeks and 3 months after V1. The third visit (V3) occurred between 1 and 7 days after V2. During V2 and V3, an ECC was performed. During this study, we added a fourth visit (V4) to measure EIB at an ambient temperature after obtaining permission from the ethics committee.

The study was approved by the ethics committee of Goethe University. The study was registered in clinical trials under registration number NCT02026492.

\section{Subjects}

We recruited 78 subjects aged 6 to 40 years with asthmatic symptoms while exercising with at least 1-2 training sessions per week. The children were recruited mainly from our outpatient clinic for pulmonology and allergology, and the remaining children and all adults were recruited by a public posting. Inhaled corticosteroids (ICSs) and leukotriene receptor antagonists (LTRA) were stopped from 14 days prior to participating in the study until the completion of the final study visit $[25,26]$. According to the exclusion criteria, we did not include subjects with $\mathrm{FEV}_{1}<75 \%$, a forced vital capacity $<80 \%$, a recent course of oral corticosteroids or other known chronic diseases or infections. Moreover, pregnancy, smoking, documented alcohol and/or drug abuse and inability to perform all study procedures were exclusion criteria for study participation.

\section{Pulmonary function test}

Baseline pulmonary function tests were performed using a MasterScreen spirometer (CareFusion, Germany) as previously described [27]. 


\section{Methacholine challenge}

The MCT was performed as previously described [16] using an Aerosol Provocation System (APS, MedicAid-dosimeter; CareFusion, Germany).

The doses of inhaled methacholine at a concentration of $16 \mathrm{mg} / \mathrm{mL}$ were increased according to the following pattern from step 1 to 5: 0.01, 0.1, 0.4, 0.8, and $1.6 \mathrm{mg}$. Two minutes after each inhalation, spirometry was performed, and the provocation was stopped under a decrease in $\mathrm{FEV}_{1}$ of $20 \%$ or more was reached. The individual provocation dose causing a $20 \%$ decrease in $\mathrm{FEV}_{1}\left(\mathrm{PD}_{20} \mathrm{FEV}_{1}\right)$ following methacholine was calculated by logarithmic interpolation using an integrated program. A $\mathrm{PD}_{20} \mathrm{FEV}_{1}<1 \mathrm{mg}$ was considered a positive reaction.

\section{Exercise challenge at an ambient temperature and in a cold chamber}

The ECC was performed according to the ATS guidelines for the diagnosis of EIB [5] and as previously described [27]. The exercise challenge at an ambient temperature was performed similarly without using the cold chamber.

At $24 \mathrm{~h}$ prior to exercise challenge the subjects had to refrain from sports activities and the use of short-acting $\beta_{2}$-agonists. A decrease in $\mathrm{FEV}_{1} \geq 10 \%$ in the spirometry assessments conducted 5, 10, 15 and $30 \mathrm{~min}$ after running was considered as a positive reaction.

\section{Statistical analyses}

We used GraphPad Prism 5.01 (GraphPad Software Inc., La Jolla, CA, USA), BiAS for Windows TM (version 11.0, Epsilon-Publisher, Frankfurt, Germany) and Microsoft Excel for the statistical analysis of the anonymized data.

According to the Kolmogorov-Smirnov test, the normally distributed data are expressed as the mean and standard deviation, while the non-normally distributed data are expressed as the median and minimum/maximum $(\mathrm{min} / \mathrm{max})$. If the $\mathrm{FEV}_{1}$ values after exercise were higher than the baseline values, they were considered a zero \% decrease in $\mathrm{FEV}_{1}$ for better comparability with a similar study [12].

A receiver-operating characteristic (ROC) curve was plotted for the surrogate markers with significant Spearman's rank correlations to the maximal $\mathrm{FEV}_{1}$ decrease in the ECC. The cut-off level with the optimal combination of sensitivity and specificity was calculated using the Youden index (sensitivity + specificity-1). The AUC reflects the accuracy of the surrogate markers in predicting a positive reaction in the ECC. Significance was set at $p<0.05$.

The AUC was calculated as an integral from point zero to $30 \mathrm{~min}\left(\mathrm{AUC}_{0-30 \mathrm{~min}}\right)$. The relationship between the maximum decreases in $\mathrm{FEV}_{1}$ after exercise and the $\mathrm{AUC}_{0-30 \mathrm{~min}}$ was described by a Spearman's rank correlation test.

The repeatability was evaluated using the method described by Bland and Altman [28]. Therefore, the difference between the first and second ECC is plotted against the mean of the two ECCs with the maximum $\mathrm{FEV}_{1}$, and the mean and SD of the differences between the two measurements along with the 95\% limits of agreement (95\%LOAs; mean difference \pm 1.96 SDs) were calculated [28].

\section{Results}

\section{Patient characteristics}

Seventy-eight subjects were recruited. Two subjects did not fulfil the inclusion criteria; therefore, 76 subjects were included in the study. Five participants dropped out after V1 (one participant due to pregnancy, one participant due to a car accident, one participant withdrew consent, and two participants were lost to follow-up). Seventy-one subjects completed the first ECC on V2. Four participants dropped out between V2 and V3 as follows: one participant had a viral infection of the upper airway tract, and three participants were lost to follow-up. Sixty-seven subjects completed the second ECC at V3. Therefore, in total, 67 subjects completed both ECCs and were used for the statistical calculations.

Fifty-one of the 67 subjects (76.1\%) were willing to participate in the exercise challenge at an ambient temperature (Fig. 1). Thirty-one subjects (46.3\%) suffered from rhinoconjunctivitis symptoms, 14 subjects (20.9\%) reported coughing during the pollen season and 21 subjects $(31.3 \%)$ had physician diagnosed asthma; of these subjects, eight subjects (11.9\%) took ICS on a regular basis, none of the subjects took LTRA and 35 subjects (52.2\%) used short-acting $\beta_{2}$-agonists as rescue medication. The mean baseline $\mathrm{FEV}_{1}$ value was $97.8 \% \pm$ 13.0. The characteristics of the subjects and $\mathrm{FEV}_{1}$ values are summarized in Table 1 . Regarding the $\mathrm{FEV}_{1}$ and FVC manoeuvres, the ATS/European Respiratory Society test criteria for acceptability and repeatability were met [29].

\section{Overview of the reactions to the ECCs, exercise challenge} at an ambient temperature and MCT

During the first ECC, 44 of the 67 subjects (65.7\%) exhibited a significant reaction with a median decline in $\mathrm{FEV}_{1}$ among all subjects of $14.9 \%(0.0-46.1)$; during the second ECC 36 of the 67 subjects (53.7\%) exhibited a reaction with a median decline in $\mathrm{FEV}_{1}$ among all subjects of 9.9\% (0.0-52.2). The median $\mathrm{AUC}_{0^{-} 30 \mathrm{~min}}$ of the entire group was a $226.6 \%$ decrease in $\mathrm{FEV}_{1} /$ min $(0.0-1045.0)$ after the first ECC and $149.4 \%$ decrease in the $\mathrm{FEV}_{1} / \mathrm{min}$ $(0.0-1115.0)$ after the second ECC. The data of the 


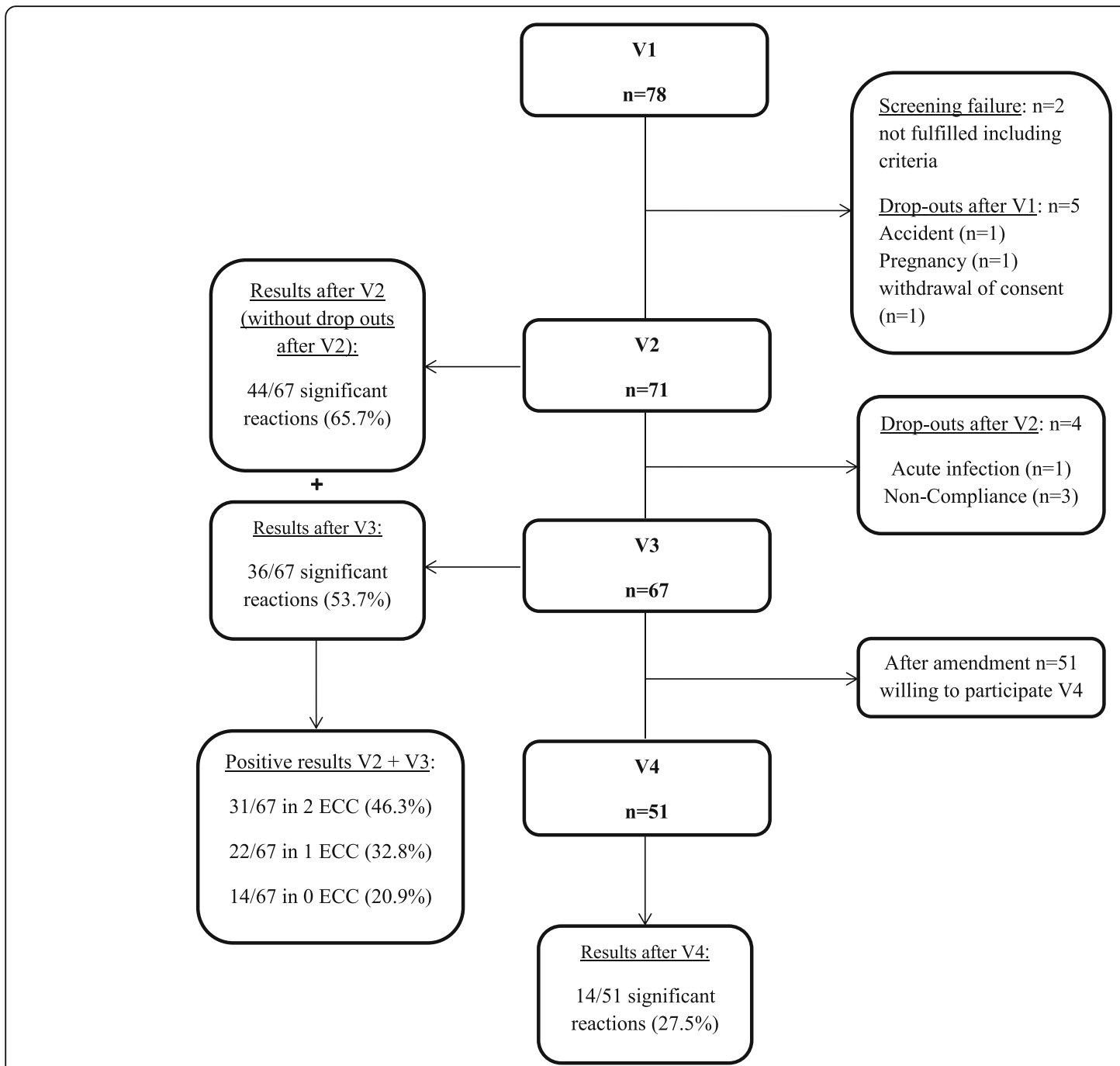

Fig. 1 Screened subjects, included subjects, drop outs and outcome

Table 1 Patient's characteristics

\begin{tabular}{|c|c|c|c|c|}
\hline & & Children & Adults & Total \\
\hline & & 6-17 years & $18-40$ years & \\
\hline Subjects & {$[n]$} & 35 & 32 & 67 \\
\hline Female / Male & {$[n]$} & $14 / 21$ & $22 / 10$ & $36 / 31$ \\
\hline Age & {$[\mathrm{yr}]$} & $12.1 \pm 2.9$ & $25.6 \pm 5.8$ & $18.6 \pm 8.1$ \\
\hline Height & {$[\mathrm{m}]$} & $1.56(1.27-1.81)$ & $1.7(1.55-1.9)$ & $1.65(1.27-1.9)$ \\
\hline Weight & {$[\mathrm{kg}]$} & $51.4(24.0-70.8)$ & $65.4(54.2-110.8)$ & $58.1(24.0-110.8)$ \\
\hline $\mathrm{FEV}_{1}$ & [\%pred] & $98.6 \pm 12.8$ & $97.1 \pm 13.4$ & $97.8 \pm 13.0$ \\
\hline $\mathrm{PD}_{20} \mathrm{FEV}_{1}$ & {$[\mathrm{mg}]$} & $1.3(0.01-2.9)$ & $0.8(0.01-4.5)$ & $0.86(0.01-4.5)$ \\
\hline $\mathrm{AQL}$ & & $\begin{array}{l}\text { ACT }(<12 \mathrm{yr}) \\
23(19-27) \\
n=15\end{array}$ & $\begin{array}{l}\text { ACQ }(\geq 12 \mathrm{yr}) \\
0.43(0-2.7) \\
n=50\end{array}$ & \\
\hline
\end{tabular}

normally distributed data mean \pm SD

not normally distributed data median and $\mathrm{min} / \mathrm{max}$

$\mathrm{SD}$, standard deviation; FVC, forced vital capacity; $F E V_{1}$, forced expiratory volume in one second; $\mathrm{PD}_{20} \mathrm{FEV}_{1}$ metha, provocation dose of methacholine causing a $20 \%$ drop in $\mathrm{FEV}_{1} ; \mathrm{AQL}$, asthma quality of life; $\mathrm{ACT}$, asthma control test (cut off well controlled $\geq 20$ ); $\mathrm{ACQ}$, asthma control questionnaire (cut off well controlled $\leq 0.75$ ), two subjects $\geq 12$ yr did not complete the ACQ; $n$, number; yr., years; m, meter; kg, kilogram; \%pred, \%predicted; mg, milligram; ppb, parts per billion 
decrease in $\mathrm{FEV}_{1}$ and the $\mathrm{AUC}_{0^{-} 30 \mathrm{~min}}$ of the whole group and separately among the children and adults are listed in Table 2.

Thirty-one subjects (46.3\%) exhibited a positive reaction with a decrease in $\mathrm{FEV}_{1} \geq 10 \%$ from the baseline value in both ECCs; 22 subjects (32.8\%) showed a positive reaction in only one of the two challenges; and 14 subjects $(20.9 \%)$ did not significantly positively react in any of the challenges.

During the exercise challenge at an ambient temperature, 14 of the 51 subjects (27.5\%) exhibited a positive reaction with a mean decrease in $\mathrm{FEV}_{1}$ of $5.5 \%$ (0.0-35.8) (Fig. 1, Fig. 2 a).

The methacholine test was positive in 37 of the 67 subjects (55.2\%). The overlaps in the reactions during the first ECC, MCT and exercise challenge at an ambient temperature are displayed in Fig. $2 \mathrm{~b}$ and $\mathrm{c}$.

There was a statistically significant difference between the patients with and without physician diagnosed asthma, a higher $\mathrm{FEV}_{1}$ decrease was observed in both ECCs (first ECC $p<0.01$, second ECC $p<0.001$ ) and a lower $\mathrm{PD}_{20} \mathrm{FEV}_{1}$ of methacholine was observed in the methacholine challenge $(\mathrm{p}<0.001)$ but not the exercise challenge in an ambient temperature $(p=0.22)$.

\section{Predictors of exercise-induced bronchoconstriction in a cold chamber}

The ROC curves were calculated to evaluate the sensitivity and specificity of different surrogate markers for the prediction of a positive reaction during the first ECC. As surrogate markers, the $\mathrm{PD}_{20} \mathrm{FEV}_{1}$ of methacholine, the maximal decrease in $\mathrm{FEV}_{1}$ during the second ECC and the exercise challenge at an ambient temperature were used. These three parameters were significantly correlated with the maximal decrease in $\mathrm{FEV}_{1}$ during the first ECC as a requirement of the ROC analysis $\left[\mathrm{PD}_{20} \mathrm{FEV}_{1}\right.$ of methacholine: $\mathrm{r}=-0.38(p<0.001)$, maximal decrease in $\mathrm{FEV}_{1}$ during ECC: $\mathrm{r}=0.58(\mathrm{p}<0.001)$, maximal decrease in $\mathrm{FEV}_{1}$ during exercise challenges at an ambient temperature: $\mathrm{r}=0.39(p<0.01)$ ].

Regarding the $\mathrm{PD}_{20} \mathrm{FEV}_{1}$ of methacholine, the optimal cut-off value of $1.36 \mathrm{mg}$ resulted in a sensitivity of $86 \%$ and a specificity of $52 \%$ (AUC $0.69, p<0.05$ ). Eleven of the 49 patients with a $\mathrm{PD}_{20} \mathrm{FEV}_{1}$ of methacholine below the cut-off value did not show EIB, indicating a PPV of $78 \%$. Six of the 18 patients with a $\mathrm{PD}_{20} \mathrm{FEV}_{1}$ of methacholine above the cut-off value exhibited EIB, yielding an NPV of $67 \%$ (Fig. 3). In addition, after the first ECC, the optimum cut-off value for predicting a second positive ECC was $8.5 \%$ with a sensitivity of $75 \%$ and a specificity of $78 \%$ (AUC $0.78, p<0.001$ ). Five of the 39 patients with an $\mathrm{FEV}_{1}$ decrease over the cut-off value did not exhibit EIB in the ECC during V2, indicating a PPV of $87 \%$. Ten of the 28 patients with an $\mathrm{FEV}_{1}$ decrease under the cut-off value exhibited EIB in the ECC during V2, yielding an NPV of 64\% (Fig. 3).

The maximal $\mathrm{FEV}_{1}$ decrease in the exercise challenge at an ambient temperature could not significantly predict a positive reaction to the exercise challenge in the cold chamber [optimal cut-off decrease of $\mathrm{FEV}_{1} 5.2 \%$, sensitivity 61\%, specificity 73\% (AUC 0.64, $p=0.13$ )] (data not shown).

\section{Reproducibility of exercise-induced bronchoconstriction in a cold chamber}

In the comparison of both ECCs, the Spearman's rank correlation of the maximal $\mathrm{FEV}_{1}$ decrease was $\mathrm{r}=0.58$ $(p<0.001)$ in the entire group. The agreement between the two ECCs was expressed according to the method proposed by Bland and Altman as upper and lower 95\% limits of agreement (95\% LOAs); regarding the maximal decrease in $\mathrm{FEV}_{1}$, the $95 \% \mathrm{LOAs}$ ranged from $-17.7-26.4 \%$. In Fig. 4 a, the difference between the first and second measurement is plotted against the mean of the two measurements of the maximum $\mathrm{FEV}_{1}$ decrease $[28,30]$.

A comparison of the results of the $\mathrm{AUC}_{0-30 \mathrm{~min}}$ revealed a Spearman's rank correlation of $0.60(\mathrm{p}<0.001)$ and repeatability according to Bland and Altman, with 95\% LOAs of $-315.7-504.7 \%$ (Fig. 4 b).

There was no significant difference in the mean $\mathrm{FEV}_{1}$ decrease after exercise between the children and adults (Table 2). Compared with the children group, we observed a better Spearman's rank correlation between the maximal $\mathrm{FEV}_{1}$ decrease and the $\mathrm{AUC}_{0-30 \min }$ in the adult group. The correlation and repeatability data according

Table 2 Exercise challenge in a cold chamber

\begin{tabular}{|c|c|c|c|c|c|c|c|}
\hline & & \multicolumn{3}{|l|}{ ECC 1 (V2) } & \multicolumn{3}{|l|}{ ECC 2 (V3) } \\
\hline & & $\begin{array}{l}\text { Total } \\
n=67\end{array}$ & $\begin{array}{l}\text { Children } \\
n=35\end{array}$ & $\begin{array}{l}\text { Adults } \\
n=32\end{array}$ & $\begin{array}{l}\text { Total } \\
n=67\end{array}$ & $\begin{array}{l}\text { Children } \\
n=35\end{array}$ & $\begin{array}{l}\text { Adults } \\
n=32\end{array}$ \\
\hline $\begin{array}{l}\text { max. FEV } \\
\text { decrease }\end{array}$ & {$[\%]$} & $14.5(0.0-64.2)$ & $14.1(1.5-64.2)$ & $14.9(0.0-46.1$ & $10.7(0.0-52.5)$ & $10.8(0.0-38.5)$ & $9.87(0.0-25.5)$ \\
\hline$A \cup C_{0-30 \min }$ & [\%fall FEV $\left.\mathrm{F}_{1} / \mathrm{min}\right]$ & $226.6(0.0-1045.0)$ & $217.2(15.6-1045.0)$ & $264.7(0.0-1007.0)$ & $149.4(0.0-1115.0)$ & $174.5(0.0-1115.0)$ & $133.1(0.0-894.4)$ \\
\hline
\end{tabular}

All values mean $\pm S D$

ECC Exercise challenge in a cold chamber, V2 Visit 2, V3 Visit 3, SD Standard deviation, FEV 1 Forced expiratory volume in one second, AUC Area under the curve, $p$ $p$-value, Mann-Whitney-Test (non-parametric distribution), $p$-values: difference between child and adult group; all not significant 


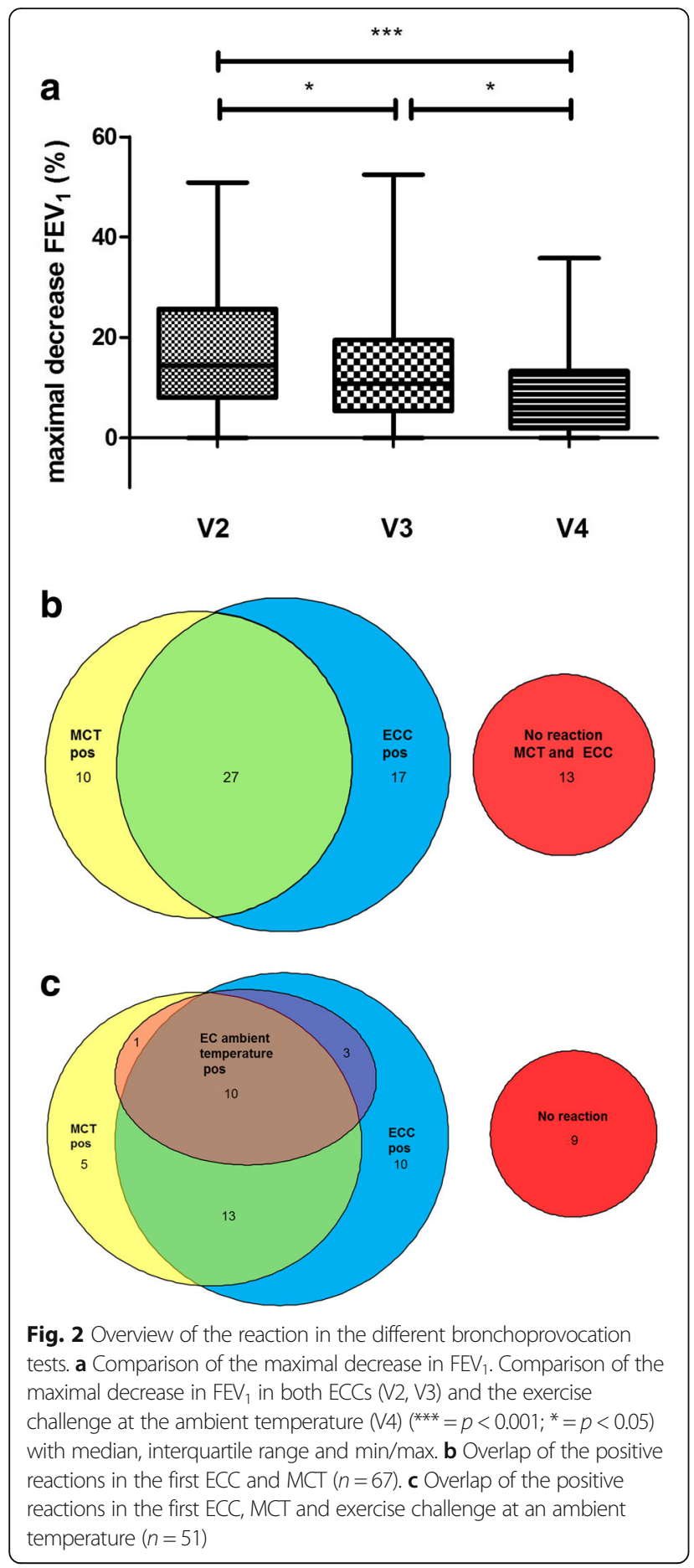

to Bland and Altman (of the whole group and separately for the children and adults) are shown in Tables 3 and 4 .

\section{Discussion}

The aim of the present study was to establish and to re-evaluate the combination of two indirect stimuli, i.e., exercise and cold air, using a new ECC, to achieve a higher sensitivity and reproducibility in detecting EIB. In

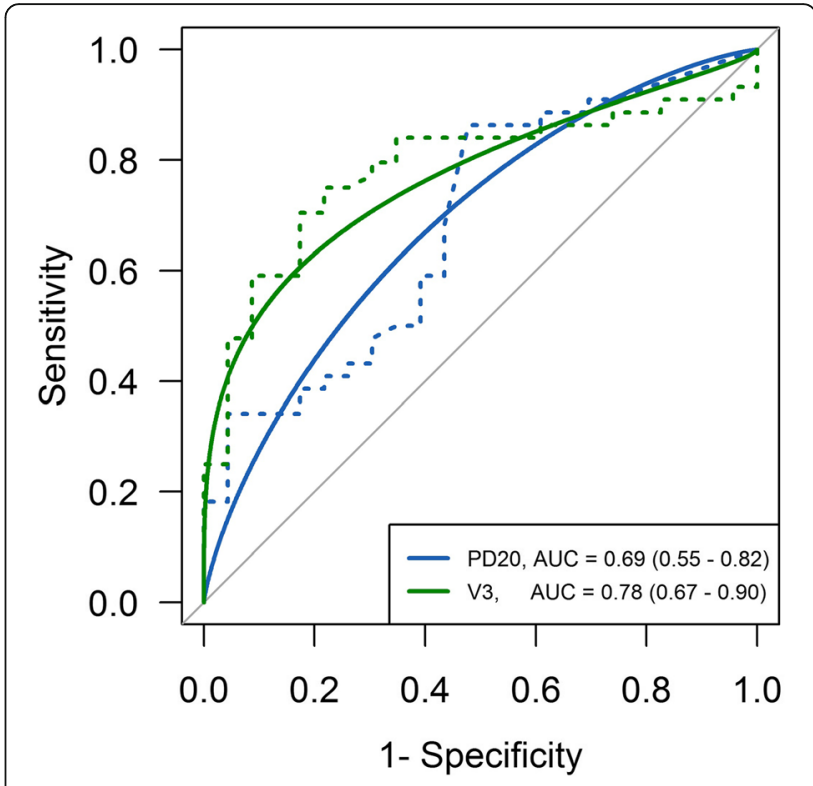

Fig. 3 Receiver-operating characteristic curve for predicting a positive decrease in $\mathrm{FEV}_{1}$ after ECC. $\mathrm{PD}_{20} \mathrm{FEV}_{1}$ of methacholine: Optimal cut-off, 1.36 mg; sensitivity, 86\%; specificity, 52\%; and AUC, $0.69(p<0.05)$. $\mathrm{FEV}_{1}$ decrease during exercise challenge in a cold chamber: Optimal cut-off, 8.5\%; sensitivity, 75\%; specificity, 78\%; and AUC, $0.78(p<0.001)$

addition, we investigated whether MCT and exercise at an ambient temperature are possible predictors of EIB using ECC as a new diagnostic tool. This analysis was performed to demonstrate for the inexperienced physicians that running at an ambient temperature has a poor sensitivity and MCT has a poor specificity in the diagnosis of EIB to underline the need for our new ECC.

In our study, the optimum cut-off value for the MCT was a $\mathrm{PD}_{20} \mathrm{FEV}_{1}$ of methacholine of $1.36 \mathrm{mg}$ to predict a positive reaction in the ECC with a sensitivity of $85 \%$ and a specificity of $52 \%$.

The MCT is a well-established method used to assess bronchial hyper-responsiveness (BHR) [16, 18-20]. BHR to methacholine follows a logarithmic order [31]. Therefore, the cut-off of $1.36 \mathrm{mg}$ of methacholine is similar to the cut-off of $1 \mathrm{mg}$ of methacholine used to predict the concentration of $8 \mathrm{mg} / \mathrm{mL}$ methacholine and is considered the usually accepted cut-off point for BHR [16]. This finding is consistent with earlier studies showing that MCT has a sensitivity of $70 \%$ and a specificity of $54.5 \%$ in predicting a positive reaction during a standardized treadmill exercise challenge in dry air in 509 patients with mild, stable asthma [11]. In a recent study involving children with asthma-like symptoms and allergic sensitization, the reactions to methacholine, mannitol, a bronchodilator test and an exercise challenge were compared [17]. The authors found BHR in $93.5 \%$ of the children with a positivity ratio of $91.1 \%$ for methacholine 


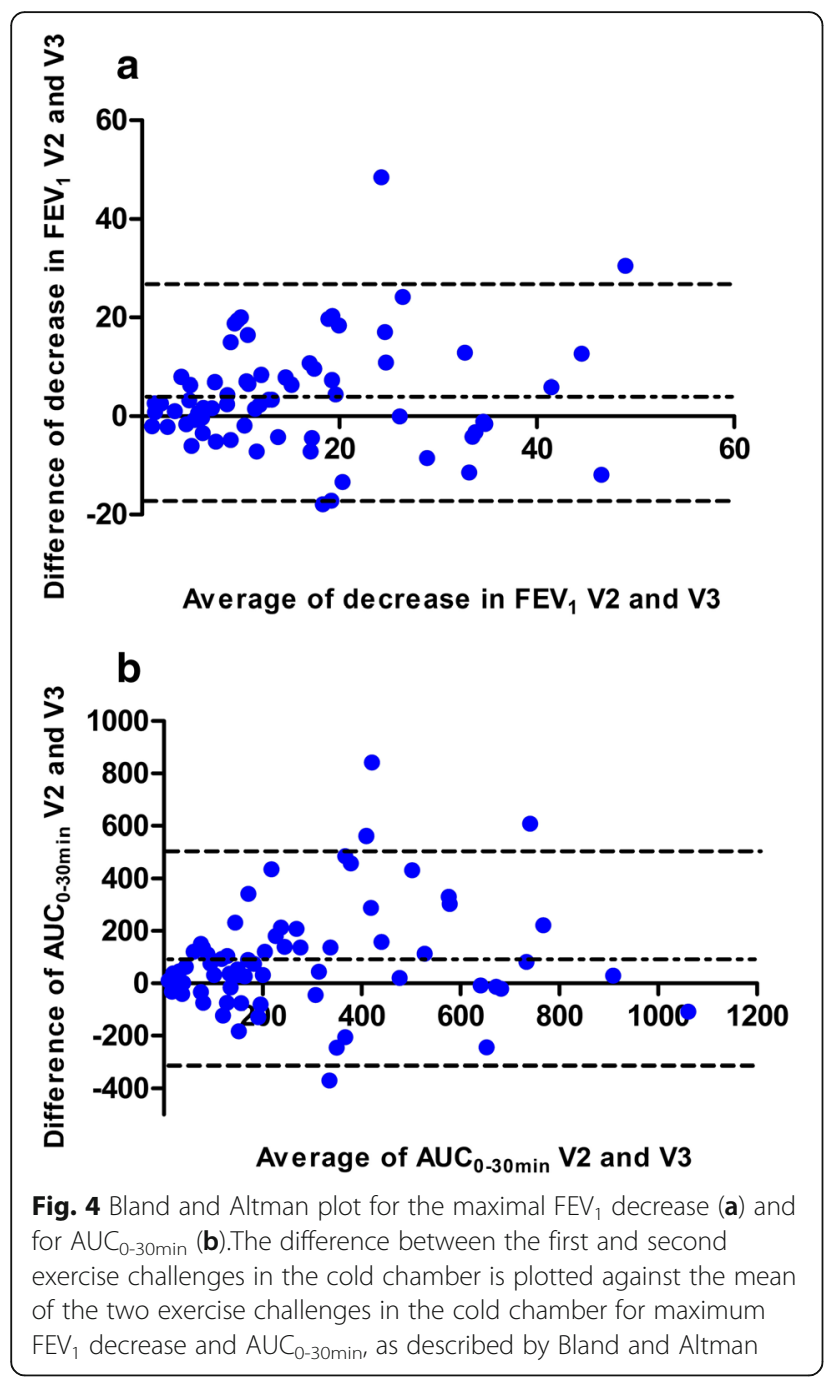

and $80 \%$ for mannitol. The authors concluded that a combination of both tests, i.e., a combination of a direct and an indirect challenge, increases the detection of BHR to $100 \%$. The authors explain their findings with the fact that a direct test is more sensitive and an indirect test is more specific for EIB as both tests investigate different components of airway dysfunction [2, 9, 10, 32]. We confirm the finding that a direct challenge is more sensitive (methacholine test: sensitivity $86 \%$, specificity $52 \%$ ) and an indirect challenge is more specific

Table 3 Comparison of the two ECC - Spearman Correlation

\begin{tabular}{|c|c|c|c|}
\hline & Total $n=67$ & Children $n=35$ & Adults $n=32$ \\
\hline \multicolumn{4}{|l|}{ Maximal FEV ${ }_{1}$ decrease } \\
\hline Spearman Correlation & $0.58^{* *}$ & $0.46^{*}$ & $0.77^{* *}$ \\
\hline \multicolumn{4}{|l|}{$A \cup C_{0-30 \min }$} \\
\hline Spearman Correlation & $0.60^{* *}$ & $0.34^{*}$ & $0.85^{* *}$ \\
\hline
\end{tabular}

$\mathrm{FEV}_{1}$, forced expiratory volume in one second; AUC, area under the curve ${ }^{*}, p$ value $<0.01 i^{* *}, p$ value $<0.001$ (prediction decrease $\mathrm{FEV}_{1}$ in cold chamber: sensitivity $75 \%$, specificity 78\%). Therefore, compared with the MCT, an ECC is superior in diagnosing EIB. The ATS guidelines state that MCT is more useful for excluding a diagnosis of asthma because of its negative predictive power [26]. However, in a large multi-centre study, 73 of 163 subjects (45\%) who were positive following an exercise challenge were negative following the methacholine challenge [11]. Anderson and Brannan [33] concluded that an EIB diagnosis should not be excluded on the basis of a negative MCT.

Interestingly, a maximal $\mathrm{FEV}_{1}$ decrease of $8.5 \%$ during the ECC significantly predicted the second positive ECC with a sensitivity of $75 \%$ and a specificity of $78 \%$, whereas the maximal $\mathrm{FEV}_{1}$ decrease in an exercise challenge at an ambient temperature was not predictive. Similar results were found in patients with mild, stable asthma in a standardized exercise challenge on a treadmill while inhaling medical dry air [11]. Consistent with the literature, our study shows that an exercise challenge at an ambient temperature detects only a low percentage of subjects with EIB $[15,17]$. This finding has been well known since the famous investigations performed by McFadden, who found that the severity of exercise-induced asthma varies according to the type of exercise and the environment [14]. The authors elegantly showed that running during the winter is a greater challenge for patients with asthma than running during the summer. This finding was confirmed by another study [10], which showed that combining cold air and exercise significantly increased the sensitivity of detecting exercise-induced asthma. Cold air is low in water content; thus, both cold air and dry air trigger the same mechanism, i.e. increased osmolarity in the bronchial tissue, provoking airway smooth muscle contraction $[2,3,7,8]$. At $100 \%$ relative humidity, the water concentration in air at $37^{\circ} \mathrm{C}$ is 44 $\mathrm{mg} / \mathrm{L}$; however, at $-10,0$, and $+10^{\circ} \mathrm{C}$ at $100 \%$ relative humidity, the water content is 3,5 and $9 \mathrm{mg} / \mathrm{L}$, respectively [34]. The ATS Guidelines [5] recommend a water concentration $<10 \mathrm{mg} / \mathrm{L}$ for an exercise challenge to detect EIB. Our cold chamber has a temperature of $2^{\circ} \mathrm{C}$ and $70-80 \%$ humidity, which is equivalent to a water content of 5-6 $\mathrm{mg} / \mathrm{L}$. Notably, a diagnosis of EIB has to be transferred to the real-life situation of the subjects. Of course, athletes exercising in cold and dry air are more affected by a diagnosis of EIB and need more treatment than subjects participating in sports at ambient temperature. However, importantly, the water content in our ECC corresponds to the average water content in our region during the autumn, winter and spring. Moreover, Rundell et al. [35] conclude that cold dry air and near maximal exercise intensity are critical components in an exercise challenge for the detection of EIB.

Subsequently, we investigated the reproducibility of our method on the basis of the decrease in $\mathrm{FEV}_{1}$ and $\mathrm{AUC}_{0-30 \mathrm{~min}}$. The AUC summarizes the extent and 
Table 4 Comparison of the two ECC - Bland and Altman

\begin{tabular}{|c|c|c|c|c|c|}
\hline & & Mean [\%] & SD & $95 \% \mathrm{Cl}$ & 95\% LOAs \\
\hline \multirow[t]{3}{*}{ Maximal decrease $\mathrm{FEV}_{1}$} & $\begin{array}{l}\text { Total } \\
n=67\end{array}$ & 4.3 & 11.25 & $1.56-7.06$ & $-17.7-26.4$ \\
\hline & $\begin{array}{l}\text { Children } \\
n=35\end{array}$ & 5.4 & 13.04 & $0.90-9.86$ & $-20.2-30.9$ \\
\hline & $\begin{array}{l}\text { Adults } \\
n=32\end{array}$ & 3.2 & 8.96 & $-0.07-6.39$ & $-14.5-20.9$ \\
\hline \multirow[t]{3}{*}{$A \cup C_{0-30 m i n}$} & $\begin{array}{l}\text { Total } \\
n=67\end{array}$ & 94.4 & 209.31 & $43.35-145.46$ & $-315.7-504.7$ \\
\hline & $\begin{array}{l}\text { Children } \\
n=35\end{array}$ & 116.4 & 253.22 & $28.02-204.72$ & $-379.9-612.7$ \\
\hline & $\begin{array}{l}\text { Adults } \\
n=32\end{array}$ & 71.8 & 152.30 & $17.76-125.77$ & $-226.8-370.3$ \\
\hline
\end{tabular}

The agreement between the two exercise challenges was expressed according to the method of Bland and Altman

Mean, mean difference of all values, SD Standard deviation of the mean difference of all values, $95 \% \mathrm{Cl} 95 \%$ Confidence interval of the mean difference of all values, $95 \%$ LOAs $95 \%$ Limits of agreement - range of FEV1 values in the next ECC

The $95 \% \mathrm{Cl}$ of the maximal decrease in FEV1 does not include the zero, the maximal decrease in FEV1 were averaged higher than those in the second ECC

duration of bronchoconstriction and, therefore, is appropriate for investigating the effect of medication on post-exercise reactions [12]. Compared with the studies conducted by Anderson et al. [12] and Dahlén et al. [13], we demonstrated similar 95\% LOAs in the decrease in $\mathrm{FEV}_{1}$ and $\mathrm{AUC}_{0-30 \mathrm{~min}}$ in the Bland and Altman plots of the entire group. There was no significant difference between the adults and children in the $\mathrm{FEV}_{1}$ decrease and $\mathrm{AUC}_{0-30 \mathrm{~min}}$ after the ECC; however, we observed a greater variation in the children's values. This variation leads to slightly lower correlation coefficients, wider $95 \%$ LOAs according to Bland and Altman and, consequently, lower reproducibility. This finding is consistent with a similar study in which the authors did not find significant differences in the response between adults and children, but the values for of the 95\% LOAs of $\mathrm{FEV}_{1}$ and $\mathrm{AUC}_{0-30 \mathrm{~min}}$ revealed a wider distribution in the values of the children [12].

Although our LOAs are similar to those reported in other studies using an exercise challenge in dry air [12, 13], they seem poorer than those in an investigation using $\mathrm{EVH}$ in athletic individuals (LOAs - 10.7 to 9.5\%) [36]. In this study mainly healthy subjects were challenged with EVH, only 6 of 32 athletes (19\%) suffered from physician-diagnosed mild asthma resulting in only 7 athletes (21.9\%) exhibiting an $\mathrm{FEV}_{1}$ decrease $\geq 10 \%$ after both EVH challenges, 17 (53.1\%) did not exhibit an $\mathrm{FEV}_{1}$ decrease $\geq 10 \%$ at all, and only 4 athletes exhibited an $\mathrm{FEV}_{1}$ decrease $\geq 20 \%$ after EVH challenge [36]. This prompted us to analyze our subjects with an $\mathrm{FEV}_{1}$ decrease $<20 \%(n=43),<15 \%(n=35)$ and $<10 \%(n=23)$ in the first ECC. The LOAs were improving ranging from -14.3 to $17.1 \%,-13.1$ to $11.4 \%$ and -11.2 to $9.3 \%$ respectively. Consequently we can conclude that the LOAs increase with the distributional width of the $\mathrm{FEV}_{1}$ decreases after EIB challenge and thus with the amount of subjects suffering from mild to severe BHR. Therefore, in order to compare different EIB challenge methods similar composition of the study population is essential.

The difference in the maximal decrease in the $\mathrm{FEV}_{1}$ values between the first and second ECC is difficult to explain. The temperature, humidity and protocol used for the treadmill exercise were identical. We speculate that the subjects were less nervous and more relaxed during the ECC, and thus, there was some type of habituation effect during the second ECC.

Another important finding is the cut-off value for a positive exercise challenge. According to the ATS guidelines, we chose an $\mathrm{FEV}_{1}$ decrease of $\geq 10 \%$ as the cut-off $[5,26,37-40]$. This cut-off was based on the mean plus two SDs of the percent decrease in $\mathrm{FEV}_{1}$ in healthy subjects after an exercise challenge as described in previous studies [5, 35, 41-43]. Higher cut-off values provide higher specificity and less false positive results but lower sensitivity. In a previous meta-analysis, a cut-off value of $\geq 13 \% \mathrm{FEV}_{1}$ decrease with sensitivity of $62.3 \%$ and specificity of $94.2 \%$ was found to be optimal [44]. Other studies recommend using an $\mathrm{FEV}_{1}$ decrease $\geq 15 \%$ as the cut-off $[5,45]$, especially in field based exercise challenges $[3,46]$.

There are some clinical limitations to our study. First, the exercise challenge at an ambient temperature was added after the start of our study. Therefore, not all subjects underwent this challenge, and the sample size was smaller than that in the ECC analysis. Nevertheless, we could clearly show that cold air is more potent than ambient temperatures for detecting EIB. Second, it would have been preferable if the subjects practiced the ECC prior to performing it for a reproducibility test to minimize the habituation effect and not influence reproducibility. In addition, since we did not investigate control subjects, the false positive predictive value of the 
ECC could not be defined by our results, representing a bias and a drawback of our study.

An advantage of our method in the cold chamber is the comfortable free-run on a treadmill without wearing a facemask, which we believe is more comfortable, especially for children.

\section{Conclusions}

In summary, the parameters $\mathrm{PD}_{20} \mathrm{FEV}_{1}$ of methacholine and the maximal $\mathrm{FEV}_{1}$ decrease in cold air were statistically significant in predicting a positive reaction during an ECC, whereas the maximal $\mathrm{FEV}_{1}$ decrease during an exercise challenge at an ambient temperature was not predictive.

The MCT is more sensitive and the ECC is more specific for EIB. The current and former data do not support the concept that a negative MCT excludes EIB.

We confirm that an exercise challenge at an ambient temperature detects only a low percentage of subjects with EIB $[15,17]$. For confirming the diagnosis of EIB, a provocation test combining two stimuli, i.e. exercise and dry air, is essential as this approach increases the sensitivity of detecting EIB $[10,14]$ and is the current gold standard according to the ATS Guidelines [5].

To the best of our knowledge, the predictor $\mathrm{PD}_{20} \mathrm{FEV}_{1}$ of methacholine and the reproducibility of the exercise challenge were previously investigated at ambient temperatures and with the combination of exercise and dry air only but not in an ECC [11, 17, 21-24].

With our ECC, we can achieve similar reproducibility in adult patients in accordance with previous studies, using a combination of the exercise challenge and dry air. Consequently, our ECC is a good diagnostic tool and could serve as a standardized diagnostic of EIB used for the clinical testing of anti-inflammatory medications.

\section{Abbreviations \\ 95\% Cl: 95\% Confidence interval; 95\% LOA: 95\% Limits of agreement; ACT: Asthma control test; APS: Aerosol Provocation System; AQL: Asthma quality of life; ATS: American Thoracic Society; $\mathrm{AUC}_{0^{-} 30 \mathrm{~min}}$ : Area under the curve at 0-30 min; BHR: Bronchial hyper-responsiveness; ECC: Exercise challenge in a cold chamber; EIB: Exercise-induced bronchoconstriction; $\mathrm{EVH}$ : Eucapnic voluntary hyperventilation; $\mathrm{FEV}_{1}$ : Forced expiratory volume in 1 s; FVC: Forced vital capacity; ICS: Inhaled corticosteroid; LTRA: Leukotriene receptor antagonists; MCT: Methacholine challenge test; mg: Milligrams; NPV: Negative predictive value; $\mathrm{PD}_{20} \mathrm{FEV}_{1}$ of methacholine: Provocation dose of methacholine causing a 20\% decrease in $\mathrm{FEV}_{1}$; ppb: Parts per billion; PPV: Positive predictive value; ROC: Receiver-operator characteristic; SD: Standard deviation; V1/2/3/4: Visits 1/2/3/4}

\section{Acknowledgements}

The purchase of the cold chamber was supported by a grant from the "Kinderhilfestiftung Frankfurt am Main. e.V." and Mrs. J. Zivanovic-Riedel.

\section{Funding}

Not applicable.

\section{Availability of data and materials}

The datasets generated and analysed in the current study are not publicly available because they are stored on our clinic computer, and only members of our department can access this computer, but the data are available from the corresponding author upon reasonable request.

\section{Authors' contributions}

$\mathrm{MD}$ contributed to the analysis and interpretation of the data and drafted the article. JS contributed to the conception and design, participated in the data acquisition, analysis and interpretation and critically revised the article. TF and NL contributed to the data acquisition, analysis and interpretation and critically revised the article. EH contributed to the data analysis and interpretation and critically revised the article. SZ contributed to the conception and design, data acquisition and critical revision of the article. All authors approved the final version of the manuscript.

\section{Ethics approval and consent to participate}

Participation in this study was voluntary. Prior to the commencement of the first visit, written informed consent was required from each subject or the parents of children under the age of 18 years. The study was approved by the ethics committee of Goethe University (reference number 208/13).

\section{Consent for publication}

Not applicable.

\section{Competing interests}

The authors declare that they have no competing interests.

\section{Publisher's Note}

Springer Nature remains neutral with regard to jurisdictional claims in published maps and institutional affiliations.

\section{Author details}

${ }^{1}$ Division of Pulmonology, Allergy and Cystic Fibrosis, Department of Paediatric and Adolescent medicine, University Hospital Frankfurt, Theodor-Stern-Kai 7, 60590 Frankfurt am Main, Germany. ${ }^{2}$ Institute of Biostatistics and Mathematical Modelling, Goethe-University, Frankfurt, Germany.

Received: 1 August 2017 Accepted: 11 April 2019

Published online: 16 May 2019

\section{References}

1. Brasholt M, Baty F, Bisgaard H. Physical activity in young children is reduced with increasing bronchial responsiveness. J Allergy Clin Immunol. 2010;125: 1007-12.

2. Weiler JM, Bonini S, Coifman R, Craig T, Delgado L, Capão-Filipe M, et al. American Academy of Allergy, Asthma \& Immunology work group report: exercise-induced asthma. J Allergy Clin Immunol. 2007;119:1349-58.

3. Rundell KW, Slee JB. Exercise and other indirect challenges to demonstrate asthma or exercise-induced bronchoconstriction in athletes. J Allergy Clin Immunol. 2008;122:238-46 quiz 247-8.

4. Carlsen KCL, Håland G, Devulapalli CS, Munthe-Kaas M, Pettersen M, Granum $\mathrm{B}$, et al. Asthma in every fifth child in Oslo, Norway: a 10-year follow up of a birth cohort study. Allergy. 2006;61:454-60.

5. Parsons JP, Hallstrand TS, Mastronarde JG, Kaminsky DA, Rundell KW, Hull

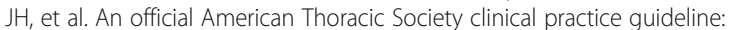
exercise-induced bronchoconstriction. Am J Respir Crit Care Med. 2013;187: 1016-27.

6. Parsons JP, Kaeding C, Phillips G, Jarjoura D, Wadley G, Mastronarde JG. Prevalence of exercise-induced bronchospasm in a cohort of varsity college athletes. Med Sci Sports Exerc. 2007;39:1487-92.

7. Boulet L, O'Byrne PM. Asthma and exercise-induced bronchoconstriction in athletes. N Engl J Med. 2015;372:641-8.

8. Carlsen K. Sports in extreme conditions: the impact of exercise in cold temperatures on asthma and bronchial hyper-responsiveness in athletes. $\mathrm{Br}$ J Sports Med. 2012;46:796-9.

9. Henriksen $\mathrm{AH}$, Tveit $\mathrm{KH}$, Holmen $\mathrm{TL}$, Sue-Chu M, Bjermer L. A study of the association between exercise-induced wheeze and exercise versus methacholine-induced bronchoconstriction in adolescents. Pediatr Allergy Immunol. 2002;13:203-8.

10. Carlsen KH, Engh G, Mørk M, Schrøder E. Cold air inhalation and exerciseinduced bronchoconstriction in relationship to metacholine bronchial 
responsiveness: different patterns in asthmatic children and children with other chronic lung diseases. Respir Med. 1998;92:308-15.

11. Anderson SD, Charlton B, Weiler JM, Nichols S, Spector SL, Pearlman DS. Comparison of mannitol and methacholine to predict exercise-induced bronchoconstriction and a clinical diagnosis of asthma. Respir Res. 2009;10:4.

12. Anderson SD, Pearlman DS, Rundell KW, Perry CP, Boushey H, Sorkness CA et al. Reproducibility of the airway response to an exercise protocol standardized for intensity, duration, and inspired air conditions, in subjects with symptoms suggestive of asthma. Respir Res. 2010;11:120.

13. Dahlén B, O'Byrne PM, Watson RM, Roquet A, Larsen F, Inman MD. The reproducibility and sample size requirements of exercise-induced bronchoconstriction measurements. Eur Respir J. 2001;17:581-8.

14. McFadden ER, Gilbert IA. Exercise-induced asthma. N Engl J Med. 1994;330:1362-7.

15. Avital A, Godfrey S, Springer C. Exercise, methacholine, and adenosine 5'monophosphate challenges in children with asthma: relation to severity of the disease. Pediatr Pulmonol. 2000;30:207-14.

16. Schulze J, Rosewich M, Riemer C, Dressler M, Rose MA, Zielen S. Methacholine challenge--comparison of an ATS protocol to a new rapid single concentration technique. Respir Med. 2009;103:1898-903.

17. Sánchez-García S, Rodríguez del Río P, Escudero C, García-Fernández C, Ibáñez MD. Exercise-induced bronchospasm diagnosis in children. Utility of combined lung function tests. Pediatr Allergy Immunol. 2015;26:73-9.

18. Schulze J, Biedebach S, Christmann M, Herrmann E, Voss S, Zielen S. Impulse Oscillometry as a predictor of asthma exacerbations in young children. Respiration. 2016;91:107-14.

19. Schulze J, Smith H, Fuchs J, Herrmann E, Dressler M, Rose MA, Zielen S. Methacholine challenge in young children as evaluated by spirometry and impulse oscillometry. Respir Med. 2012;106:627-34.

20. Schulze J, Reinmüller W, Herrmann E, Rosewich M, Rose MA, Zielen S. Bronchial allergen challenges in children - safety and predictors. Pediatr Allergy Immunol. 2013;24:19-27.

21. ElHalawani SM, Ly NT, Mahon RT, Amundson DE. Exhaled nitric oxide as a predictor of exercise-induced bronchoconstriction. Chest. 2003;124:639-43.

22. Buchvald F, Hermansen MN, Nielsen KG, Bisgaard $H$. Exhaled nitric oxide predicts exercise-induced bronchoconstriction in asthmatic school children. Chest. 2005;128:1964-7.

23. Grzelewski T, Grzelewska A, Majak P, Stelmach W, Kowalska A, Stelmach R, et al. Fractional exhaled nitric oxide (FeNO) may predict exercise-induced bronchoconstriction (EIB) in schoolchildren with atopic asthma. Nitric Oxide. 2012;27:82-7.

24. Lex C, Dymek S, Heying R, Kovacevic A, Kramm CM, Schuster A. Value of surrogate tests to predict exercise-induced bronchoconstriction in atopic childhood asthma. Pediatr Pulmonol. 2007;42:225-30.

25. Vathenen AS, Knox AJ, Wisniewski A, Tattersfield AE. Time course of change in bronchial reactivity with an inhaled corticosteroid in asthma. Am Rev Respir Dis. 1991;143:1317-21.

26. Crapo RO, Casaburi R, Coates AL, Enright PL, Hankinson JL, Irvin CG, et al. Guidelines for methacholine and exercise challenge testing-1999. This official statement of the American Thoracic Society was adopted by the ATS Board of directors, July 1999. Am J Respir Crit Care Med. 2000;161:309-29.

27. Dreßler M, Salzmann-Manrique E, Zielen S, Schulze J. Exhaled NO as a predictor of exercise-induced asthma in cold air. Nitric Oxide. 2018;76:45-52.

28. Bland JM, Altman DG. Applying the right statistics: analyses of measurement studies. Ultrasound Obstet Gynecol. 2003;22:85-93. https:/doi.org/10.1002/uog.122.

29. Miller MR, Hankinson J, Brusasco V, Burgos F, Casaburi R, Coates A, et al. Standardisation of spirometry. Eur Respir J. 2005;26:319-38.

30. Bland JM, Altman DG. Agreed statistics: measurement method comparison. Anesthesiology. 2012;116:182-5.

31. Guidelines for standardization of bronchial challenges with (nonspecific) bronchoconstricting agents. Bull Eur Physiopathol Respir. 1983;19:495-514.

32. Clough JB, Hutchinson SA, Williams JD, Holgate ST. Airway response to exercise and methacholine in children with respiratory symptoms. Arch Dis Child. 1991;66:579-83.

33. Anderson SD, Brannan JD. Methods for "indirect" challenge tests including exercise, eucapnic voluntary hyperpnea, and hypertonic aerosols. Clin Rev Allergy Immunol. 2003;24:27-54.

34. Rundell KW, Anderson SD, Sue-Chu M, Bougault V, Boulet L. Air quality and temperature effects on exercise-induced bronchoconstriction. Compr Physiol. 2015;5:579-610.
35. Rundell KW, Wilber RL, Szmedra L, Jenkinson DM, Mayers LB, Im J. Exerciseinduced asthma screening of elite athletes: field versus laboratory exercise challenge. Med Sci Sports Exerc. 2000;32:309-16.

36. Price OJ, Ansley L, Hull JH. Diagnosing exercise-induced bronchoconstriction with eucapnic voluntary hyperpnea: is one test enough? J Allergy Clin Immunol Pract. 2015;3:243-9.

37. Carlsen KH, Anderson SD, Bjermer L, Bonini S, Brusasco V, Canonica W, et al. Exercise-induced asthma, respiratory and allergic disorders in elite athletes: epidemiology, mechanisms and diagnosis: part I of the report from the joint Task Force of the European Respiratory Society (ERS) and the European academy of allergy and clinical immunology (EAACI) in cooperation with GA2LEN. Allergy. 2008;63:387-403.

38. Task Force ERS. Clinical exercise testing with reference to lung diseases: indications, standardization and interpretation strategies. ERS Task Force on Standardization of Clinical Exercise Testing European Respiratory Society Eur Respir J. 1997;10:2662-89.

39. Sterk PJ, Fabbri LM, Quanjer PH, Cockcroft DW, O'Byrne PM, Anderson SD, et al. Airway responsiveness. Standardized challenge testing with pharmacological, physical and sensitizing stimuli in adults. Report working party standardization of lung function tests, European Community for steel and coal. Official statement of the European Respiratory Society. Eur Respir J Suppl. 1993;16:53-83.

40. Weiler JM, Brannan JD, Randolph CC, Hallstrand TS, Parsons J, Silvers W, et al. Exercise-induced bronchoconstriction update-2016. J Allergy Clin Immunol. 2016;138:1292-5 e36.

41. Custovic A, Arifhodzic N, Robinson A, Woodcock A. Exercise testing revisited. The response to exercise in normal and atopic children. Chest. 1994;105:1127-32

42. Kattan M, Keens TG, Mellis CM, Levison $H$. The response to exercise in normal and asthmatic children. J Pediatr. 1978;92:718-21.

43. Helenius IJ, Tikkanen HO, Haahtela T. Occurrence of exercise induced bronchospasm in elite runners: dependence on atopy and exposure to cold air and pollen. Br J Sports Med. 1998:32:125-9.

44. Godfrey S, Springer C, Bar-Yishay E, Avital A. Cut-off points defining normal and asthmatic bronchial reactivity to exercise and inhalation challenges in children and young adults. Eur Respir J. 1999;14:659-68.

45. Buhl R, Berdel D, Criée C, Gillissen A, Kardos P, Kroegel C, et al. Leitlinie zur Diagnostik und Therapie von Patienten mit Asthma -- Herausgegeben von der Deutschen Atemwegsliga und der Deutschen Gesellschaft für Pneumologie und Beatmungsmedizin e. V Pneumologie. 2006;60:139-77.

46. Anderson SD. Indirect' challenges from science to clinical practice. Eur Clin Respir J. 2016:3:31096.

\section{Ready to submit your research? Choose BMC and benefit from:}

- fast, convenient online submission

- thorough peer review by experienced researchers in your field

- rapid publication on acceptance

- support for research data, including large and complex data types

- gold Open Access which fosters wider collaboration and increased citations

- maximum visibility for your research: over $100 \mathrm{M}$ website views per year

At $\mathrm{BMC}$, research is always in progress.

Learn more biomedcentral.com/submission 